\title{
Psicologia Escolar em discussão
}

\section{School Psychology in discution}

\section{Joly, M. C. R. A. \& Vectore, C. (2006) Questões de pesquisa e práticas em psicologia escolar. São Paulo: Casa do Psicólogo}

A Psicologia é uma ciência que não diz respeito apenas a um ramo específico do conhecimento humano, tornando-se há pouco mais de 40 anos, uma atividade profissional devidamente regulamentada, enquanto ciência e profissão. Um dos setores da Psicologia voltado para a atuação e investigação em contextos educacionais é a Psicologia Escolar e Educacional. O livro "Questões de pesquisa e práticas em Psicologia Escolar" organizado por Maria Cristina Rodrigues Azevedo Joly e Célia Vectore, teve como foco, estudos e pesquisas na área da psicologia escolar e educacional. Deste modo, este livro reúne textos com temáticas que visam ampliar as discussões e especialmente as ações do psicólogo escolar.

O capítulo inicial, Metacognição e Cloze na avaliação de dificuldades em leitura escrito por Maria Cristina Rodrigues Azevedo Joly e Janete Aparecida da Silva Marini, discute a ampla temática da leitura focando a metacognição e a técnica de Cloze na avaliação de dificuldades apresentadas nessa habilidade. Versa sobre a importância do auto monitoramento de seu processo de leitura, por parte do leitor, para que neste sentido seja possível implementar ações para a avaliação das dificuldades de compreensão em relação ao processo, visando um ensino mais eficaz.

No capítulo seguinte Produção auto-regulada de textos: considerações para a escolarização inicial, Elis Regina da Costa e Evely Boruchovitch discutem a produção auto-regulada de textos relacionada à escolarização inicial. É interessante observar que, dentro deste contexto, escrever claramente é uma necessidade que distingue alunos com alto e baixo desempenho. É válido esclarecer aos educadores que inúmeras são as situações que podem e devem ser criadas para desencadear produções textuais e que propostas de produção auto-regulada de textos têm muito a contribuir para enriquecer a capacidade de escrever dos alunos.

Ana Paula Cabral contribuiu com o texto Fórmulas de intervenção nos domínios da compreensão em leitura e escrita no ensino superior. É de grande importância o destaque dado às competências de leitura, compreensão e análise que possibilitam sucesso no ensino superior, conforme exposto pela autora em relação às fórmulas de intervenção nos domínios da compreensão em leitura e escrita, incentivando a criação e o desenvolvimento de sistemas de apoio que permitem aos alunos adquirirem e aperfeiçoarem as suas competências no segmento.

Em seguida, as autoras Mirthis Czubka de Abreu, Maria Cristina Rodrigues Azevedo Joly e Nayane Martoni Piovezan escreveram o capítulo Escala de estratégias metacognitivas de leitura: caracterização de uso por universitários paulistas e mineiros, que discute a escala de estratégias metacognitivas de leitura utilizada por universitários paulistas e mineiros. Foram analisadas as diferenças do uso das estratégias de acordo com idade, gênero e influência do curso e semestre freqüentados, podendo ser consideradas evidências de validade para a escala. Foram identificadas diferenças significativas em relação às análises feitas pelo uso da escala por estudantes de diferentes estados enfatizando a importância de novos estudos com maior número de participantes por regiões.

Eunice M. L. Soriano de Alencar escreveu o capítulo $O$ papel do psicólogo escolar na prevenção de dificuldades socioemocionais do aluno com altas habilidades, onde são apresentadas recentes pesquisas com alunos superdotados em seu desenvolvimento sócioemocional, as quais relatam o estudo de variáveis que se referem à prevenção e diminuição do desajuste emocional dos mesmos, otimizando o processo de 
desenvolvimento, levando em consideração o papel do psicólogo escolar na prevenção de dificuldades socioemocionais desses alunos.

Desenvolvimento da criatividade no contexto escolar: integrando características personológicas e fatores ambientais, é o capítulo escrito por Denise de Souza Fleith. A autora destaca o papel fundamental da escola como um ambiente marcante, que pode proporcionar uma aprendizagem prazerosa, contextualizada, que possibilite a expressão das qualidades e habilidades dos alunos, ao abordar o desenvolvimento da criatividade no contexto escolar, integrando características personológicas e fatores ambientais.

A construção dialética da adição e da subtração no jogo Gamão é o capítulo abordado por Maria José de Castro Silva e Rosely Palermo Brenelli. O texto tratase de um relato de pesquisa que objetivou verificar as relações existentes entre a construção dialética das operações de adição e subtração e o tipo de estratégia utilizada pelos jogadores durante a partida de Gamão. De maneira geral, os dados obtidos com a pesquisa forneceram valiosas informações sobre as dificuldades apresentadas pelos participantes. Assim, pode-se perceber relações entre a construção dialética da adição e da subtração e as condutas adotadas pelo aluno na escolha de estratégias utilizadas no jogo.

Em Aprendizagem de conceitos estatísticos em estudantes de diferentes níveis de ensino, as autoras Claudette Maria Medeiros Vendramini, Anelise Silva Dias e Marjorie Cristina Rocha da Silva, abordam a aprendizagem de conceitos estatísticos em estudantes de diferentes níveis de ensino. A pesquisa relatada constatou que as dificuldades apresentadas pelos alunos em relação aos conceitos matemáticos surgem a partir do ensino fundamental, isto posto, consideram necessário inserir conceitos, visando o desenvolvimento da habilidade de leitura e compreensão de dados estatísticos desde o início da vida acadêmica.

No capítulo Tecnologias da informação e comunicação: avaliação de desempenho dos estudantes, Ronei Ximenes Martins descreveu as tecnologias da informação e comunicação por meio de uma avaliação de desempenho dos estudantes. Em seu relato de pesquisa demonstrou a condição dos alunos quanto ao uso de tecnologias no ensino médio, os quais já pos- suem grande capacidade para sua utilização. Tal estudo poderá ajudar na orientação de atividades educacionais utilizando essas tecnologias, proporcionando um possível diagnóstico quanto ao sucesso e dificuldades em relação a atividades educacionais tecnológicas.

A pesquisa qualitativa assim como a sua importância para a compreensão dos processos escolares foram os assuntos abordados por Marilene Proença Rebello de Souza no texto Pesquisa qualitativa e sua importância para a compreensão dos processos escolares. A autora discute a importância de uma perspectiva etnográfica como abordagem qualitativa para compreensão dos processos do cotidiano escolar.

No capítulo Dialogando sobre o tempo livre com os participantes da pesquisa, os autores Jorge Castellá Sarriera, Ângela Carina Paradiso, Denise Carvalho Tatim e Gabriela Howes, procuraram apontar a importância da devolução dos dados levantados aos participantes da pesquisa, sua verificação, validação e desenvolvimento, considerando os aspectos éticos e metodológicos. Destacam que o processo de pesquisa incorpora a intervenção e a participação como elementos fundamentais para a pesquisa com fins sociais.

Em Concepções e práticas sobre formação em contexto: na busca de uma educação de qualidade, contribuição da autora Tizuko Morchida Kishimoto, são expostas as concepções e práticas sobre formação, objetivando uma educação de qualidade. Visando a concretização da educação com qualidade, a autora relata a inclusão de experiências do cotidiano tendo consciência da complexidade do fenômeno educativo, pois modificar os conteúdos curriculares e aprendizagem exige um processo participativo que integre a educação e o cuidado com a criança. objetivando a qualidade na educaçxige um processo participativo que integre a educaç

Alternativas para a avaliação de qualidade do atendimento na educação infantil, escrito por Célia Vectore e Cirlei Evangelista Silva Souza, relata as possibilidades para uma avaliação de qualidade do atendimento na educação Infantil, por meio de um Programa de Aprendizagem Pré-escolar efetiva (APE). As autoras demonstraram uma alternativa viável, sendo passível para ser utilizada em outros contextos nacionais, ten- 
do também como diferencial a avaliação contínua feita por todos os integrantes, sobre o andamento do projeto.

Eulália Henriques Maimone contribuiu com o texto A pesquisa colaborativa autoscópica na formação de professores da educação infantil. A autora destaca a realização do projeto $A P E$, como uma fonte de conhecimento da qualidade das relações dos pais com a instituição e nas relações adultos-crianças e entre as crianças, que podem acontecer em uma instituição de educação infantil. Indica a necessidade de mudanças nas condições do trabalho educativo por meio das observações das características das mediações das aprendizagens pelos adultos, no contexto escolar.

Tempo e lugar para brincar na contemporaneidade: sentidos e possibilidades da brincadeira infantil, foi o capítulo escrito por Beatriz Belluzo Brando Cunha e Renata Fernanda Fernandes Gomes, que descreveram a criação de espaços alternativos para a expressão da infância como algo necessário, a fim de estimu- lar as trocas de experiências, encontros e convívio social entre as crianças por meio do brincar. As brinquedotecas são recursos capazes de abrir espaço para o lúdico, que pela brincadeira favorece e incentiva atividades que oferecem condições para amenizar as desigualdades sociais e estimula as trocas de experiências e convívio social entre as crianças.

Ficou claro que a meta estabelecida por este livro foi alcançada. É de grande valia para quem trabalha e pesquisa na área da psicologia escolar e educacional, sendo também uma leitura agradável. Seu conteúdo é rico em orientações sendo recomendado a todas as pessoas envolvidas neste processo desafiador de ensino-aprendizagem, no qual se insere o psicólogo escolar.

Tatiana Cristina Teixeira Psicóloga.

Aluna do Programa de Pós-Graduação Stricto Sensu em Psicologia pela Universidade São Francisco. tatictex@hotmail.com 